\title{
Detailed Research on a Comparative Evaluation of Diclofenac Sodium Tablets Manufactured by Using DC Grade Excipients and Wet Granulation Methods
}

\author{
Divya Dhatri Kara ${ }^{1}$, Hemanth Katta Govindarajulu ${ }^{1}$, Hemamanjushree Shivaprasad ${ }^{1}$, Vamshi Krishna \\ Tippavajhala', Mahendra Joshi ${ }^{2}$, Girish Pai Kulyadi ${ }^{1, *}$
}

${ }^{1}$ Department of Pharmaceutics, Manipal College of Pharmaceutical Sciences, Manipal Academy of Higher Education, Manipal, Karnataka, INDIA.

${ }^{2}$ Research and Development, IDRS Labs Pvt. Ltd., Bangalore, Karnataka, INDIA.

\begin{abstract}
Aim: The foremost aim of the present study was to formulate a Diclofenac Sodium tablet of 50mg using the direct compression method with directly compressible (DC) grade excipient and the wet granulation method. Materials and Methods: Comparative study of evaluation parameters like micromeritic properties of directly compressible powder blends and granules obtained by wet granulation was carried out to analyze the suitable method for tabletting. Evaluation parameters such as tablet description, hardness, friability, drug content, disintegration time, and dissolution study were analyzed and compared for tablets manufactured by direct compression using DC grade excipients and wet granulation methods. Results: The results of all evaluation parameters were well within the limit as per Indian Pharmacopeia (IP). Edges and Surface morphology of tablets were studied using Scanning Electron Microscopy (SEM). In-process hold time for tablets was studied by performing hold time stability study. The present work was also focused on the comparison of tablets physicochemical properties manufactured from direct compression using DC grade excipient and wet granulation methods. Conclusion: The results of disintegration and dissolution studies revealed that the tablets manufactured using direct compression using DC grade excipients were completely disintegrated in a short time and steadily dissolved at a faster rate respectively compared to the tablet manufactured from wet granulation method. Hold time stability study showed that the directly compressible tablets were more stable than the tablet formulated using the wet granulation method.
\end{abstract}

Key words: Direct compression, Directly compressible (DC) grade excipients, Wet granulation, Scanning Electron Microscopy (SEM), Surface morphology, Hold time stability study.

\section{INTRODUCTION}

Diclofenac sodium is one of the most universally used Non-Steroidal AntiInflammatory drugs (NSAID). Diclofenac sodium is well known for its anti-inflammatory, antipyretic, and analgesic activity. Diclofenac sodium has been efficaciously used to treat the patients suffered due to rheumatoid arthritis, ortho arthritis, spondylitis, and gout. Diclofenac sodium has been also used by patients who have undergone surgeries. ${ }^{1,2}$
Diclofenac sodium acts by inhibiting the enzyme named prostaglandin synthetase. Gastrointestinal disturbance or pain, nausea, vomiting, and dizziness are some of the main adverse effects of diclofenac sodium. Oral bioavailability and excretion half-life of diclofenac sodium is around $60 \%$ and $1.1-1.8 \mathrm{~h}$ respectively. The $\mathrm{pKa}$ value of diclofenac sodium is 4.0 and Diclofenac sodium has better solubility in
Submission Date: 30-10-2020; Revision Date: 10-04-2021; Accepted Date: 29-08-2021

DOI: 10.5530/ijper.55.3s.179 Correspondence: Dr. Girish Pai Kulyadi, Department of Pharmaceutics, Manipal College of Pharmaceutical Sciences, Manipal Academy of Higher Education, Manipal-576107, Karnataka, INDIA. Phone: +91 9008135597, Email-girish.pai@manipal. edu

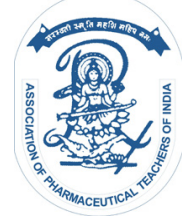

www.ijper.org 
intestinal fluid compared to acidic fluid present in the stomach. ${ }^{3}$

Tablets are the most used dosage form because of its excellent patient compliance. Among the three main methods of tablet manufacturing wet granulation and direct compression are widely used in the pharmaceutical industries. Based on API type and excipient's nature suitable tablet manufacturing method is been selected. The role of wet granulation in tablet manufacturing is remarkable for its numerous advantages like improved compressibility and cohesiveness of granules, uniform distribution of drug and colour, and improved flow property. The addition of binder solution is the crucial part of wet granulation as it facilitates the powder mixture to form wet mass later which transforms into granules to enhance the flow property of powder mixture. Binder solution also influences the dissolution rate of the poorly soluble drug. During wet granulation, process granules are screened out based on their properties like size, shape, and surface area which later influence the quality of the tablet. Despite the advantages mentioned above, the major drawback of wet granulation is the cost involved in it due to the equipment, time, and space required for the process. Although the wet granulation is expensive it is extensively used compared to the direct compression method for one or the other reason. ${ }^{4-6}$

Direct compression is a novel technique in which medium to highly potent drugs along with suitable excipients are directly compressed into tablets. This method consists of less processing steps, low energy, and time consumption. Hence, the cost of tablet manufacturing is lesser compared to wet granulation. ${ }^{7}$

Direct compression tabletting is suitable for drugs that are sensitive to moisture and heat. In addition to economic considerations and process simplification, direct compression provides many advantages in terms of process efficiency and product consistency as compared to techniques like wet granulation or pre-compression. ${ }^{8}$

Although direct compression has many advantages over wet granulation it is not widely used as a tabletting procedure because of its limitations like poor flowability of powder blend and less dilution capacity of fillers or binders that are available. Direct compression also fails to uphold the drug uniformity of low dosage forms. Excipients like fillers, binders, lubricants, or glidants play the most critical role in direct compression tabletting. ${ }^{8}$ The wise choice of excipients, when combined with the appropriate drug substance, can, however, provide a significant benefit for the establishment of a direct compression process. ${ }^{7}$

The key objective of this study was to prepare the tablets of diclofenac sodium using wet granulation and direct compression using DC grade excipients and to evaluate the tablets for their hardness, friability, drug content, disintegration time and dissolution rate. The flow properties of granules and powder blend were also evaluated to compare the efficacy of both the tableting process.

\section{MATERIALS}

Materials used for experimenting are listed in Table 1:

\section{METHODS}

\section{Pre-formulation studies of the formulation mixtures using FTIR}

FTIR 8300 spectrophotometer, Shimadzu, Japan was used to analyze the samples of pure drug, drug +(LM SD) blend, drug +(S11 SD) blend, and granules obtained from wet granulation. The samples were mixed with potassium bromide powder, and this mixture was subjected to compression for $5 \mathrm{~min}$, by applying a force of 5 tons using a hydraulic press, to form pellets. The spectra for these samples were recorded from $4000 \mathrm{~cm}^{-1}$ to $400 \mathrm{~cm}^{-1}$ range.

\section{Preparation of diclofenac sodium $(50 \mathrm{mg})$ tablet using wet granulation}

Diclofenac sodium tablets (50 mg), have been prepared using wet granulation and an extra granular method. The master formula is given in Table 2. To form a wet cohesive mass, the required amount of Diclofenac sodium, microcrystalline cellulose and lactose have been precisely weighed and evenly mixed with enough quantity of water. To get the best sizes of granules, the wet mass was passed through mesh no 12. Granules were then dried using a tray dryer for $15 \mathrm{~min}$ at $60^{\circ} \mathrm{C}$. Dried granules have again been passed via a sieve \#44 to achieve uniformity in size. Besides, sodium starch glycolate was added as an extra granulating agent in a 1:1 ratio to achieve intra-granular and extra-granular forms. The required quantity of talc and magnesium stearate were added and blended in a miniature lab sized drum blender for 30 mins.

The granules were ultimately compressed into tablets using the Rimek Minipress-I BB tooling tablet compression system of $9 \mathrm{~mm}$ of convex punches. The hardness of the tablet was determined with a computer calibrated hardness tester and was found to have an average of $3.5 \mathrm{Kg} / \mathrm{cm}^{2} .9,10$ 


\begin{tabular}{|c|c|}
\hline Material & Manufacturer \\
\hline $\begin{array}{l}\text { Diclofenac sodium (Gift } \\
\text { sample) }\end{array}$ & $\begin{array}{l}\text { ELAM PHARMA Pvt. Ltd., } \\
\text { Gujarat, India }\end{array}$ \\
\hline $\begin{array}{l}\text { Microcrystalline Cellulose } \\
\text { (Avicel PH-101) }\end{array}$ & $\begin{array}{c}\text { Signet chemical corporation, } \\
\text { Mumbai, India }\end{array}$ \\
\hline AEROSIL-200 & National chemicals, Gujarat, India \\
\hline Talc & Lobachemie, Thane, India \\
\hline Sodium starch glycolate & Lobachemie, Thane, India \\
\hline Magnesium stearate & Himedia labs, India \\
\hline Lactose & Nice laboratories, India \\
\hline $\begin{array}{l}\text { Potassium di-hydrogen } \\
\text { ortho-phosphate }\end{array}$ & $\begin{array}{l}\text { Finar Laboratories, Ahmedabad, } \\
\text { India }\end{array}$ \\
\hline Methanol & Finar Chemicals, Mumbai, India \\
\hline Sodium hydroxide pellets & Nice Chemicals, Kerala, India \\
\hline \multicolumn{2}{|c|}{ Directly Compressible (DC) grade excipients } \\
\hline $\begin{array}{l}\text { Lactose monohydrate SD } \\
\text { (LM SD) }\end{array}$ & Hospira, India \\
\hline Supertab 11 SD (S11 SD) & $\begin{array}{c}\text { Cipla (Mfd by DFE Pharma, } \\
\text { Germany) }\end{array}$ \\
\hline
\end{tabular}

\begin{tabular}{|c|c|}
\hline $\begin{array}{c}\text { Table 2: Formulation of tablets by wet granulation } \\
\text { method. }\end{array}$ \\
\hline Ingredients & (mg/tablet) \\
\hline Diclofenac sodium & $50 \mathrm{mg}$ \\
\hline Microcrystalline cellulose & $42 \mathrm{mg}$ \\
\hline Sodium starch glycolate & $22 \mathrm{mg}$ \\
\hline Talc & $2 \mathrm{mg}$ \\
\hline Magnesium stearate & $2 \mathrm{mg}$ \\
\hline Lactose & $80 \mathrm{mg}$ \\
\hline Colloidal silicon dioxide & $2 \mathrm{mg}$ \\
\hline
\end{tabular}

\section{Preparation of tablets by direct compression technique using DC grade excipients}

Diclofenac sodium tablets $50 \mathrm{mg}$ were formulated by the direct compression method using DC grade excipients as per the formula given in Table 3. Two different DC grade excipients were used for two different tablet formulations. Both the Active pharmaceutical ingredient (API) and the DC grade excipients were added and blended in a miniature lab sized drum blender for $30 \mathrm{~min}$. The mixture was then compressed into tablets using the Rimek Minipress-I BB tooling tablet compression machine of $9 \mathrm{~mm}$ concave punches. The hardness of the tablet was measured by calibrated digital hardness tester. ${ }^{11,12}$

\section{Evaluation of micromeritic properties of granules and powder blends}

Micromeritic properties of the granules prepared by wet granulation and the powder blends of both the
Table 3: Formulation of tablets by direct compression method using DC grade excipients.

\begin{tabular}{|c|c|c|}
\hline Ingredients used & Formulation 1 & Formulation 2 \\
\hline Diclofenac Sodium & $50 \mathrm{mg}$ & $50 \mathrm{mg}$ \\
\hline $\begin{array}{c}\text { Lactose } \\
\text { Monohydrate SD }\end{array}$ & $150 \mathrm{mg}$ & - \\
\hline Super TAB 11SD & - & $150 \mathrm{mg}$ \\
\hline
\end{tabular}

DC grade excipients formulations were evaluated. The official methods for evaluation of granules and powder blends include calculation of the angle of repose, bulk density, tapped density, Carr's compressibility index, or Hausner ratio.

- The angle of repose: Described as the angle between the horizontal heap surface and the sides of the heap created by the flow of granules or powder blend from the minimum height through the funnel opening. Later for the calculation of the angle of repose $(\theta)$, the height $(\mathrm{h})$ and radius ( $\mathrm{r}$ ) of the formed heap were measured and substituted in the formula mentioned below. ${ }^{13}$

$$
\theta=\tan ^{-1} \mathrm{~h} / \mathrm{r}
$$

- Bulk density and tapped density: A sample weighing about $9 \mathrm{~g}$, was added to a measuring cylinder. For calculation of bulk density in $\mathrm{g} / \mathrm{ml}$, the weight of the sample and the apparent bulk volume were noted. Based on the tapped volume obtained using Electromagnet shaker EMS-8, the tapped density was determined. ${ }^{13}$

- Carr's compressibility index and Hausner ratio: Flowability of granules or powder blend was determined by substituting bulk density and tapped density in formulas mentioned below to calculate Carr's compressibility index (CI) Eq 2 and Hausner ratio (HR) Eq 3. ${ }^{13}$

$$
\begin{gathered}
C I=\frac{\operatorname{tap} \rho-\operatorname{bulk} \rho}{\operatorname{tap} \rho} \times 100 \\
\operatorname{HR}=\frac{\operatorname{tap} \rho}{\operatorname{bulk} \rho}
\end{gathered}
$$

Where bulk is the bulk density and tap is the tapped density.

- True density: The powder density itself is called "true density". Measuring the "true density" excludes intra-particle pores volume and space filled by the voids. True density was calculated using the Solvent Displacement Method. ${ }^{14}$ 


$$
\text { True density }=\frac{\text { true weight }}{\text { true volume }}
$$

- Porosity: Porosity is the ratio of the void volume to the bulk volume of the powder. Void volume is given by subtracting the true volume of the powder from the bulk volume of the powder. ${ }^{15}$

Both the expanded porosity and the packed porosity were calculated using formulas mentioned below.

Expanded porosity:

$$
\frac{\text { true } \rho-\text { bulk } \rho}{\text { true } \rho} \times 100
$$

\section{Packed porosity:}

$$
\frac{\text { true } \rho-\operatorname{tap} \rho}{\text { true } \rho} \times 100
$$

Moisture determination: Moisture present in granules and powder mix samples was calculated by loss on the drying process. Granules and powder mix samples were dried for $10 \mathrm{~min}$ in the tray dryer. Samples have been weighed before and after the drying process. The difference in the weight is considered as the percentage of moisture content present in the sample. Moisture content was calculated using the following equation $7.4,16$

$$
\text { Moisture content }=\frac{\text { initial weight }- \text { final weight }}{\text { initial weight }} \times 100
$$

\section{Particle size determination}

Using the sieving method, the particle size was determined for the granules obtained by wet granulation and powder blends of two different formulations which were used in direct compression (prepared using DC grade excipients).

The average particle size of the samples was measured using an electromagnetic sieve shaker with mesh sizes of 10, 12, 20, 45, 60, 80, 100, and 120. Each sample weighed exactly $5 \mathrm{gm}$ and sifted for $10 \mathrm{~min}$ in a sieve shaker. The powder retained over each mesh was weighed and compared with the mesh aperture size. The powder's average particle size was the same as that of mesh aperture size upon which the maximum amount of powder is retained. ${ }^{9,17}$

\section{Evaluation of tablets}

Tablet description, Drug content, hardness, friability, disintegration time and dissolution rate for the Diclofenac sodium tablets were estimated. Tablet hardness and its friability were estimated using Electrolab THT EH 01,
Mumbai, digital hardness tester, and Electrolab EF 2, Mumbai, friability, respectively. In vitro tablet evaluation parameters like disintegration time and dissolution rate were carried out to study the tablet quality.

\section{Drug content}

Ten tablets were randomly selected and weighed to calculate the tablet's average weight. The tablets were crushed into the powder using mortar and pestle. An equivalent weight of $50 \mathrm{mg}$ of the drug diclofenac sodium from the powder blend has been weighed accurately and transferred into a $100 \mathrm{ml}$ volumetric flask. The drug was dissolved using a solvent mixture containing water and methanol in the $70: 30$ ratio. The same solvent mixture was used to make up the volume up to the mark. The contents were shaken occasionally and kept aside for $30 \mathrm{~min}$ to completely dissolve the drug. Later, the contents were filtered, and, the filtrate was diluted appropriately. The diluted sample was analyzed using a UV-Visible spectrophotometer at $276 \mathrm{~nm}$, and thus $\%$ drug content was calculated.

\section{In-vitro disintegration study}

Tablet disintegration study was performed using a disintegration apparatus (Electrolab DT Tester ED-2L, Mumbai). It consists of a basket with an assembly of six glass tubes of length $7.75 \mathrm{~cm}$ and a diameter of $2.15 \mathrm{~cm}$, the bottom of glass tubes consists of a mesh sieve of size \#10. The basket rack was moved up and down for 28-32 times per minute in the volume of $900 \mathrm{ml}$ water which was maintained at $37 \pm 0.5^{\circ} \mathrm{C}$. Disintegration time was determined by the time required for each tablet to disintegrate into fragments and passed through the \#10 sized mesh. ${ }^{10}$

\section{In vitro dissolution study}

The in vitro drug release from different tablet formulations was performed using Electrolab TDT-08L DT, Mumbai, USP 8 stationed dissolution apparatus. Type II i.e., paddle-type apparatus, was utilized to study the dissolution rate of the Diclofenac Sodium tablets $50 \mathrm{mg}$. Dissolution analysis was performed using a $6.8 \mathrm{pH}$ buffer as the dissolution medium, maintaining the temperature at $37 \pm 0.5^{\circ} \mathrm{C}$ and paddle stirring at $50 \mathrm{rpm}$. Samples of $5 \mathrm{ml}$ were withdrawn at a single time point of $60 \mathrm{~min}$ and filtered using a syringe filter. The absorbance of samples was analyzed using a UV-Visible spectrophotometer at $276 \mathrm{~nm} .^{18}$

\section{Scanning Electron Microscopy (SEM)}

SEM photomicrographs were captured using a scanning electron microscope to study the surface morphology of the tablets prepared by the different techniques. 
Tablet samples were mounted on to aluminium stub using double-sided adhesive tape. The samples were then examined under $2 \mathrm{~K}$ and $1 \mathrm{~K}$ magnification using the scanning electron microscope (ZEISS SIGMA FE-SEM). ${ }^{19,20}$

\section{Hold time stability study}

The hold time study assessment can help to determine storage periods for blend and bulk tablets of the new dosage forms in GMP conditions. According to the hold time study, the storage period for a product can be decided. For the uncoated tablets hold time study can be performed for 90 days. Two batches of all the three formulations were prepared and stored for 90 days in two different temperature conditions, one at a controlled temperature of $25^{\circ} \mathrm{C}$ and another at room temperature of $34^{\circ} \mathrm{C}$. Physico-chemical parameters like appearance, assay, hardness, friability, disintegration time, and dissolution rate were evaluated with an interval of 30 days for 3 months. ${ }^{21}$

\section{RESULTS AND DISCUSSION}

\section{Pre-formulation studies of the formulation mixtures using FTIR}

FTIR spectrum of pure diclofenac sodium illustrated in Figure 1 showed characteristic peaks at $3383.14 \mathrm{~cm}^{-1}$ for a secondary amine group (N-H stretching frequency), at $1303.88 \mathrm{~cm}^{-1}$ for C-N stretching, at $1577.77 \mathrm{~cm}^{-1}$ for a carboxylate group $(\mathrm{C}=\mathrm{O}$ stretching frequency), at $1564.27 \mathrm{~cm}^{-1}$ for $\mathrm{C}=\mathrm{C}$ stretching and at $752.24 \mathrm{~cm}^{-1}$ for C-Cl stretching. ${ }^{10,22,23}$

Table 4 demonstrated the FTIR spectra of other drugexcipients mixtures. A comparison of characteristic peaks of drug-excipient mixtures and pure drugs revealed that there is an absence of interaction between drug and excipient. Figure 2, Figure 3 and Figure 4 depicted FTIR spectra of drug + (LM SD), drug + (S11 SD), and of granules respectively.

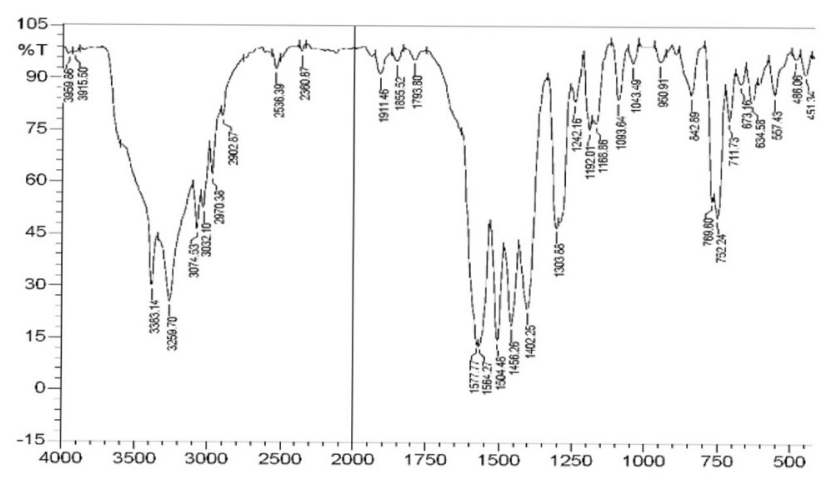

Figure 1: FTIR spectrum of pure Diclofenac sodium.

\begin{tabular}{|c|c|c|c|c|}
\hline \multicolumn{5}{|c|}{ Table 4: FTIR analysis of drug and excipients. } \\
\hline $\begin{array}{c}\text { Observed } \\
\text { peak of } \\
\text { diclofenac } \\
\text { sodium } \\
\left.\text { (cm }^{-1}\right)\end{array}$ & $\begin{array}{c}\text { Functional } \\
\text { group }\end{array}$ & $\begin{array}{c}\text { Drug + } \\
(\mathbf{L M ~ S D )} \\
\left(\mathbf{c m}^{-1}\right)\end{array}$ & $\begin{array}{c}\text { Drug + } \\
(\text { (S11 SD) } \\
\left.\text { (cm }^{-1}\right)\end{array}$ & $\begin{array}{c}\text { Granules } \\
\text { obtained } \\
\text { from wet } \\
\text { granulation }^{\left(\mathbf{c m}^{-1}\right)}\end{array}$ \\
\hline 3383.14 & $\mathrm{~N}-\mathrm{H}$ & 3381.21 & 3336.85 & 3336.45 \\
\hline 1303.88 & $\mathrm{C}-\mathrm{N}$ & 1300.02 & 1301.95 & 1305.81 \\
\hline 1564.27 & $\mathrm{C}=\mathrm{O}$ & 1568.13 & 1550.77 & 1571.99 \\
\hline 1504.48 & $\mathrm{C}=\mathrm{C}$ & 1504.48 & 1504.48 & 1504.48 \\
\hline 752.24 & $\mathrm{C}-\mathrm{Cl}$ & 754.17 & 769.60 & 748.38 \\
\hline
\end{tabular}

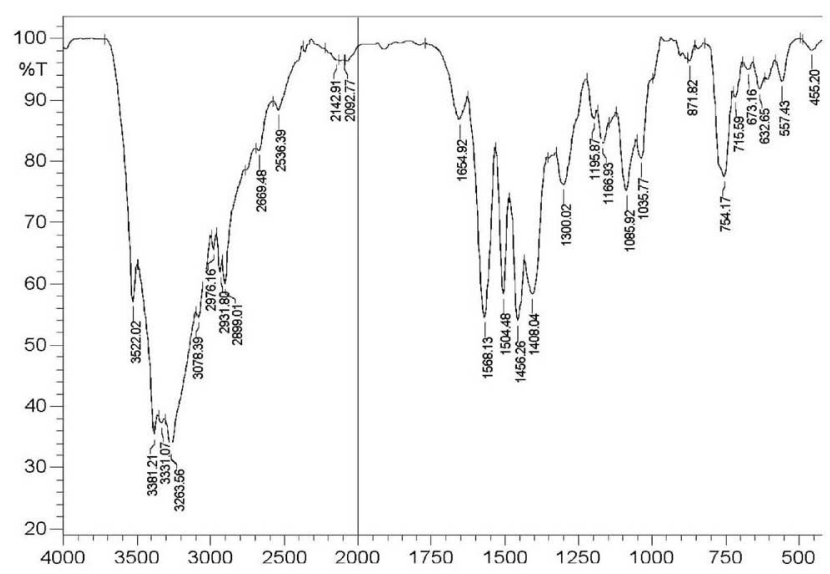

Figure 2: FTIR spectrum of the mixture containing pure drug + (LM SD).

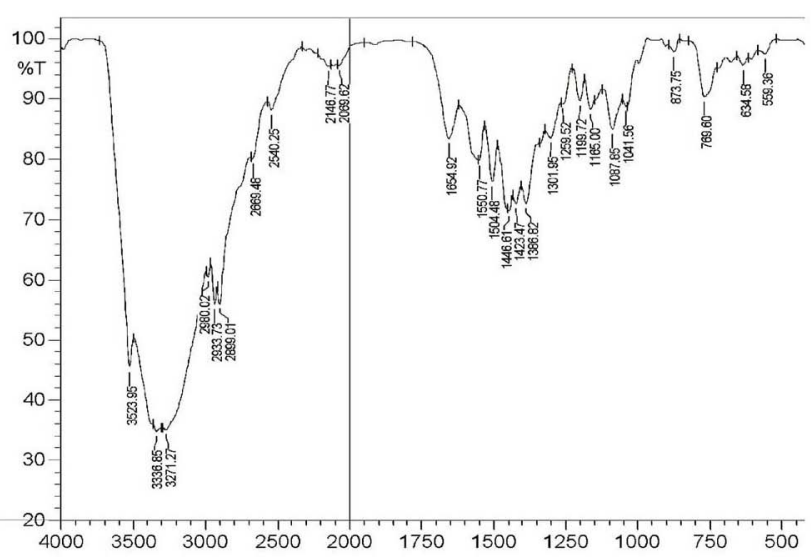

Figure 3: FTIR spectrum of the mixture containing pure drug + (S11 SD).

\section{Evaluation of micromeritic properties of powder blends and granules}

Micromeritic properties of granules obtained from the wet granulation process and powder blends of the direct compression process were evaluated using suitable procedures. The study of flow properties helps to 


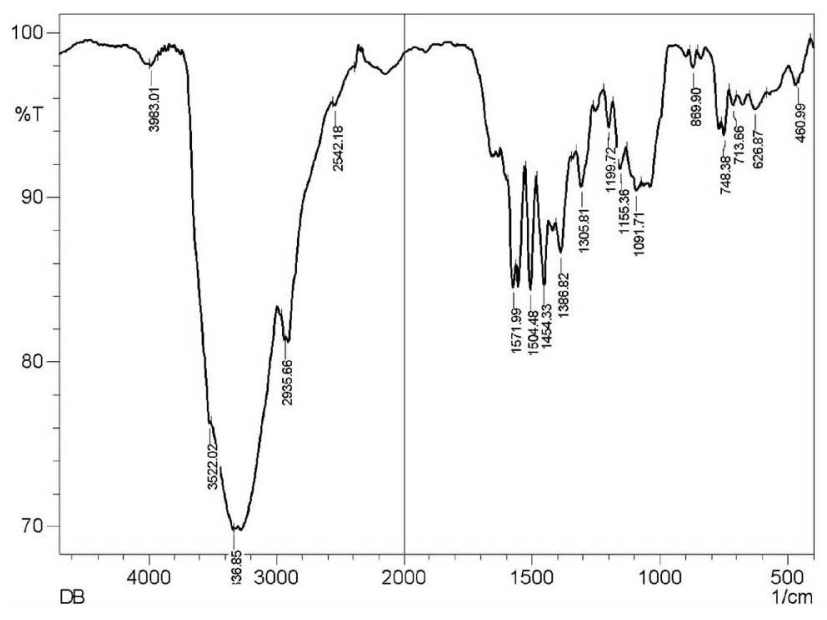

Figure 4: FTIR spectrum of the granules manufactured by wet granulation.

maintain the uniform drug distribution in tablets. One of the main tablet qualities is the maintenance of its content uniformity which can be easily achieved by studying the flow properties. Better flow properties of granules/powder blend ease the production of the uniform tablet. Flow properties like the angle of repose, bulk density, tapped density, Carr's compressibility index, Hausner ratio, true density, and porosity were evaluated and mentioned in Table 5.

\section{Moisture determination}

Moisture present in either powder blend or granules plays a prominent role in final tablet production. Moisture content above the limit affects the flow properties and also leads to microbial growth, hence it is necessary to ensure that the moisture content is within the acceptable limit. The moisture content of powder blends and granules was estimated based on equation 7 . The moisture content of powder blends such as LM SD and S11 SD was $0.6 \%$ and $0.5 \%$ respectively. Granules manufactured by wet granulation showed the moisture content of $8 \%$, which is more compared to directly compressible powder blends (a mixture of both drug and DC grade excipients).

\section{Particle size determination}

Particle size distribution and average particle size determination are some of the important quality control tests, as they influence the flow property of granules/ powders, uniform distribution of contents during tabletting, in disintegration, and dissolution process. ${ }^{24}$ As shown in Figure 5, particle size distribution curves for directly compressible powder blends exhibited narrower distribution, whereas, granules exhibited broader particle size distribution indicating an increase in polydispersity compared to directly compressible powder blends. The average particle size of the powder blends and granules are mentioned in Table 6.

\section{Evaluation of tablets}

\section{Tablet description}

Tablets prepared by both the wet granulation method and DC grade excipients were picked randomly. The tablets were individually placed on a $100 \%$ virgin A4 white paper for evaluating the appearance. Each biconvex tablet was observed using a laboratory magnifying glass to check for the presence of any black specks, contaminants, or any cracks over the surface of the tablets.

As mentioned in Table 7, tablets prepared using DC grade excipients provided white-colored tablets with a neat finish on the surfaces. Whereas, tablets prepared by wet granulation technique provided an off-white colored tablet with crooked edges.

More evaluation of this data is provided in the SEM section followed.

\section{Hardness}

Hardness is the force involved in breaking the tablet diametrically and it is also called tablet crushing strength. ${ }^{24}$ As shown in Table 7, the Hardness of directly compressible tablets i.e., formulation with LM SD and S11 SD is $8 \mathrm{~kg} / \mathrm{cm}^{2}$ and $10 \mathrm{~kg} / \mathrm{cm}^{2}$. Tablet manufactured by wet granulation exhibited the hardness of $3.0 \mathrm{~kg} / \mathrm{cm}^{2}$. Tablets manufactured from DC grade excipients were strong enough to break, hence required more force.

\section{Friability}

Along with hardness, friability also indicates the strength of the tablet. Tablets that tend to chip off or fragment when handled are not of appropriate quality. Such tablets are not acceptable by consumers hence measuring the friability is also one of the quality control tests of the tablet. \% Friability should be not more than (NMT) 1\%. Table 7 revealed the $\%$ friability of all the formulations and are well within the limit. ${ }^{6}$

\section{Drug content}

Drug content was measured using a UV-Visible spectrophotometer. A drug content study was performed to ensure the amount of the drug presented in the tablet. Variation in the amount of the drug may influence the tablet's efficacy. To ensure the efficacy and potential of the tablet, its drug content should be in the range of $90 \%-110 \%$. Table 7 presented the drug content results of all formulations and is within the limit. 


\begin{tabular}{|c|c|c|c|c|c|c|}
\hline \multicolumn{2}{|c|}{ Table 5: Flow properties of powder blends of direct compression (using DC grade excipient) formulations and } \\
granules obtained from wet granulation. & \multicolumn{3}{|c|}{ Porosity (\%) } \\
\hline Type & Angle of repose & $\begin{array}{c}\text { Carr's Index } \\
\text { (\%) }\end{array}$ & Hausner Ratio & $\begin{array}{c}\text { True Density } \\
\text { (g/ml) }\end{array}$ & \multicolumn{3}{|c|}{ expanded } & 90 & 92 \\
\cline { 3 - 7 } LM SD & $26^{\circ}$ (excellent) & $\begin{array}{c}16.71 \\
\text { (fair) }\end{array}$ & 1.2 (excellent) & 7.33 & 91.1 & 89.79 \\
\hline S11 SD & $38.5^{\circ}$ (fair) & 13.6 (excellent) & $\begin{array}{c}1.15 \\
\text { (good) }\end{array}$ & 6.47 & 87.9 & 86.8 \\
\hline $\begin{array}{c}\text { Granules (wet } \\
\text { granulation) }\end{array}$ & $26.8^{\circ}$ (excellent) & $\begin{array}{c}7 \\
\text { (excellent) }\end{array}$ & 1.08 (excellent) & 4.88 & 87 \\
\hline
\end{tabular}

\begin{tabular}{|c|c|c|c|c|}
\hline \multicolumn{5}{|c|}{ Table 6: Average particle size determination of the two powder blends and granules. } \\
\hline Mesh size & Aperture $(\mu \mathrm{m})$ & $\begin{array}{c}\text { LM SD } \\
\text { (weight retained) }\end{array}$ & $\begin{array}{c}\text { S11 SD } \\
\text { (weight retained) }\end{array}$ & $\begin{array}{c}\text { WG } \\
\text { (weight retained) }\end{array}$ \\
\hline 10 & 2000 & - & - & - \\
\hline 12 & 1405 & - & - & $0.45 \mathrm{~g}$ \\
\hline 20 & 840 & - & $0.002 \mathrm{~g}$ & $0.65 \mathrm{~g}$ \\
\hline 45 & 350 & $0.02 \mathrm{~g}$ & $0.085 \mathrm{~g}$ & $0.53 \mathrm{~g}$ \\
\hline 60 & 250 & $0.341 \mathrm{~g}$ & $2.540 \mathrm{~g}$ & $0.45 \mathrm{~g}$ \\
\hline 80 & 177 & $2.402 \mathrm{~g}$ & $1.460 \mathrm{~g}$ & $0.98 \mathrm{~g}$ \\
\hline 100 & 149 & $0.420 \mathrm{~g}$ & $0.220 \mathrm{~g}$ & $1.45 \mathrm{~g}$ \\
\hline 120 & 125 & $0.310 \mathrm{~g}$ & $0.150 \mathrm{~g}$ & $0.458 \mathrm{~g}$ \\
\hline PAN & $\leq 70$ & $0.095 \mathrm{~g}$ & $0.008 \mathrm{~g}$ & $0.032 \mathrm{~g}$ \\
\hline Average Size & & $177 \mu \mathrm{m}(50 \%)$ & $250 \mu \mathrm{m}(50 \%)$ & $149 \mu \mathrm{m} \mathrm{(50 \% )}$ \\
\hline
\end{tabular}

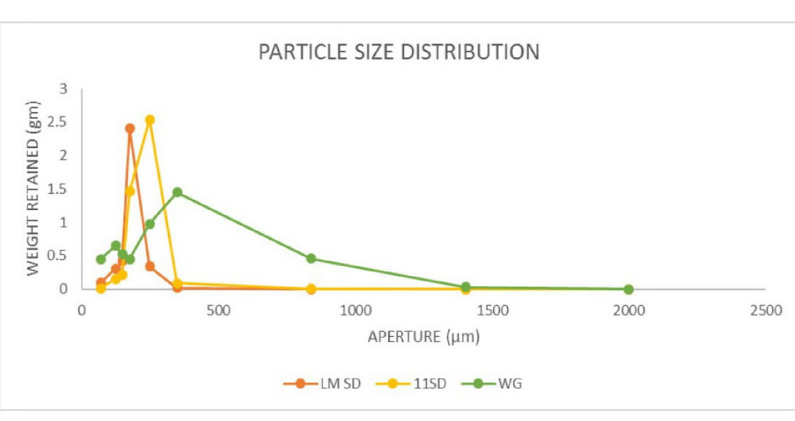

Figure 5: Particle distribution curves of directly compressible powder blends and granules manufactured by wet granulation method.

\section{In-vitro disintegration study}

Evaluation of disintegration time for a tablet is essential as it influences the drug release and absorption in the body. Most tablets show a disintegration time of not more than $30 \mathrm{~min}$. As depicted in Table 7, the disintegration time of the tablet manufactured from wet granulation was $8 \mathrm{~min}$, which was more compared to directly compressible tablets.

\section{In vitro dissolution study}

Once the tablet breaks down into fragments, it is essential to get dissolved in the surrounding medium to get absorbed into the systemic circulation. The dissolving rate is estimated in terms of the dissolution rate. According to IP, the tablet dissolution rate should not be less than 75\% Q. Table 7, illustrated that all tablet formulations are well within the limit. Tablets manufactured via direct compression using DC grade excipients such as LM SD and S11 SD showed a higher dissolution rate of $90 \% \mathrm{Q}$ and $88 \% \mathrm{Q}$ respectively compared to the tablet manufactured by wet granulation of $80.4 \%$ Q.

\section{Scanning Electron Microscopy (SEM)}

SEM was used to study the edges, surface hologram, and surface morphology of tablets manufactured by the direct compression method using DC grade excipients and wet granulation methods. Figure 6, Figure 7 and Figure 8 revealed the photomicrographs of all three formulations. As shown in Figure 6, the edges of LM SD and S11 SD were acceptable without any damages, whereas the edges of the tablet manufactured by wet 


\begin{tabular}{|c|c|c|c|c|c|c|}
\hline Formulation & Description & $\begin{array}{l}\text { Hardness } \\
\left(\mathbf{k g} / \mathrm{cm}^{2}\right)\end{array}$ & $\begin{array}{c}\text { Friability } \\
\text { (\%) }\end{array}$ & $\begin{array}{l}\text { Drug content } \\
\text { (\% Assay) }\end{array}$ & $\begin{array}{c}\text { Disintegration } \\
\text { time } \\
\text { (min) }\end{array}$ & $\begin{array}{c}\text { Dissolution rate } \\
\text { (\% Q) }\end{array}$ \\
\hline LM SD & White coloured tablets & 3 & 0.4 & 105.53 & 4'6" & 90 \\
\hline S11 SD & White coloured tablets & 8 & 0.7 & 109.97 & 4 & 88 \\
\hline WG & $\begin{array}{l}\text { Off-white coloured } \\
\text { tablets }\end{array}$ & 10 & 0.8 & 101.14 & 8 & 80.4 \\
\hline
\end{tabular}
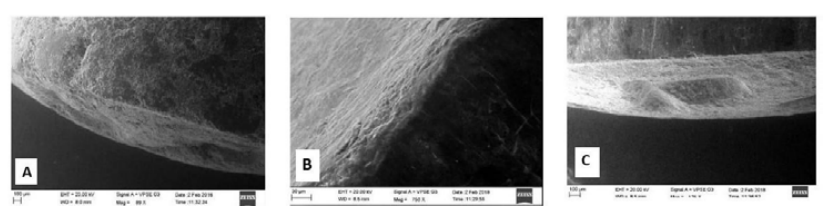

Figure 6: SEM images of the edges of the tablets (A) Tablet manufactured using wet granulation (B) Tablet containing S11 SD (DC grade) (C) Tablet containing LM SD.
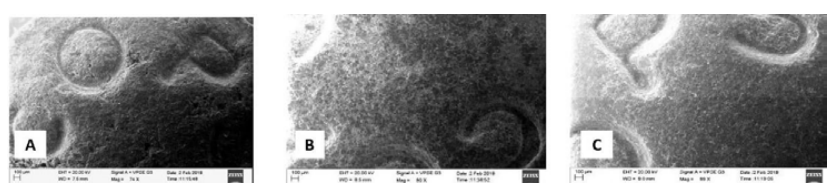

Figure 7: SEM images of the surface holograms of the tablets (A) Tablet manufactured using wet granulation (B) Tablet containing S11 SD (DC grade) (C) Tablet containing LM SD.
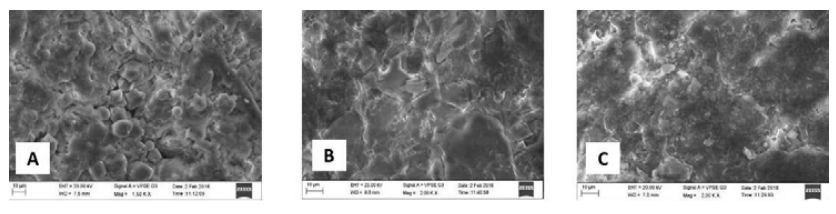

Figure 8: SEM images of the surface morphology of the tablets

(A) Tablet manufactured using wet granulation (B) Tablet containing S11 SD (DC grade) (C) Tablet containing LM SD.

granulation showed irregularity. Similarly, Figure 7 and Figure 8 also disclosed that the hologram surface and surface morphology respectively were uniform without any crooked or damaged surfaces for LM SD and S11 SD. Uneven and irregularity surface for the tablet manufactured by wet granulation is due to its broader particle size distribution, as shown in Figure 5.

\section{Hold time stability study}

Hold time stability study was performed to know the period for how long the tablets manufactured by direct compression using DC grade excipients and wet granulation could be stored until they are further processed for the enteric coating. ${ }^{21}$

Evaluation parameters of the tablet-like hardness, friability, drug content, disintegration time, and dissolution study were evaluated for all three formulations at room temperature $\left(34^{\circ} \mathrm{C}\right)$ and controlled temperature $\left(25^{\circ} \mathrm{C}\right)$ following the sample interval of 30 days for 3 months. According to the data represented in Table 8, tablets manufactured using DC grade excipients showed uniform and almost stable results for 3 months compared to the tablet manufactured by wet granulation. The data also proved that LM SD and S11 SD formulations were stable for three months.

\section{CONCLUSION}

The results of the present study revealed that the method of direct compression for tabletting is primarily recommended over the method of wet granulation because it showed better dissolution, less disintegration time, and adequate stability. Direct compression is proved as a most naive and efficient method because of its cost-effectivity which would make the tablets affordable for the necessitous patients. On the other hand, direct compression manufacturing requires minimal processing time, reduced capital, labour, energy cost, and utilities. The direct compression technique would be more beneficial for small-scale industries as it requires a smaller group of operators and equipment. It also serves to be a green manufacturing technique as it does not involve the use of any organic solvents and can be developed with a very minimum number of excipients.

The micromeritic parameters of directly compressible powder blends did not exhibit much difference compared to granules manufactured by wet granulation. But the evaluation parameters of tablets exhibited a difference between the two methods of tabletting. The hold time studies were performed to demonstrate that DC grades have the advantage of less moisture uptake and lower chemical degradation than that of the wet 
Table 8: Hold time stability study data for all three formulations.

\begin{tabular}{|c|c|c|c|c|c|c|c|c|c|c|c|c|c|c|c|}
\hline \multirow[t]{2}{*}{ Formulation } & \multicolumn{3}{|c|}{$\begin{array}{l}\text { Hardness } \\
\left(\mathrm{Kg} / \mathrm{cm}^{2}\right)\end{array}$} & \multicolumn{3}{|c|}{$\begin{array}{c}\text { Friability } \\
\text { (\%) }\end{array}$} & \multicolumn{3}{|c|}{ Drug content (\%) } & \multicolumn{3}{|c|}{$\begin{array}{l}\text { Disintegration } \\
\text { Time (min) }\end{array}$} & \multicolumn{3}{|c|}{$\begin{array}{c}\text { Dissolution rate } \\
\text { (\% CDR) }\end{array}$} \\
\hline & 1 & 2 & 3 & 1 & 2 & 3 & 1 & 2 & 3 & 1 & 2 & 3 & 1 & 2 & 3 \\
\hline LM SD (RT) & 6 & 7.1 & 9.1 & 0.4 & 0.4 & 0.38 & 105 & 104 & 95 & 6 & 7 & 7 & 89 & 90 & 83.1 \\
\hline LM SD (A/C) & 8.1 & 8.6 & 8.3 & 0.3 & 0.5 & 0.51 & 103 & 100 & 99.7 & 4.6 & 5 & 7.3 & 91 & 86 & 80.8 \\
\hline S11 SD (RT) & 10 & 10.1 & 12.9 & 0.7 & 0.8 & 0.7 & 91 & 88 & 91.5 & 4 & 6 & 9 & 98 & 83 & 81 \\
\hline S11 SD (A/C) & 11 & 11 & 11.1 & 0.7 & 0.9 & 0.9 & 109 & 105 & 103 & 5.2 & 7 & 8.1 & 84 & 75 & 77 \\
\hline WG (RT) & 3.2 & 6 & 7.2 & 0.8 & 0.4 & 0.41 & 101 & 92 & 63 & 8 & 15 & 21 & 80 & 19 & 21.31 \\
\hline WG $(A / C)$ & 3 & 5 & 5.8 & 1.0 & 0.5 & 0.3 & 111 & 97 & 88 & 11.2 & 16 & 22.1 & 90 & 54 & 33 \\
\hline
\end{tabular}

granulation technique. The quality of the tablet as a final product is depended on the method of tabletting. Through this work, we can agree that the direct compression method using the DC grade excipients can produce better quality tablets compared to wet granulation.

\section{ACKNOWLEDGEMENT}

The authors are thankful to Manipal College of pharmaceutical Sciences, Manipal Academy of Higher Education (MAHE) and IDRS Labs for providing their technical support.

\section{CONFLICT OF INTEREST}

The authors declare no conflicts of interest.

\section{ABBREVIATIONS}

DC: Directly compressible; IP: Indian Pharmacopeia; SEM: Scanning Electron Microscopy; NSAID: NonSteroidal Anti-Inflammatory drugs; CI: Carr's compressibility index; HR: Hausner ratio; GMP: Good Manufacturing Practices; FTIR: Fourier Transform Infrared Spectroscopy; NMT: Not more than.

\section{REFERENCES}

1. Al-Sharkawi MS. A multicentre study of diclofenac sodium slowrelease (Voltaren® Retard) in the treatment of rheumatic disorders in the Kingdom of Saudi Arabia. J Int Med Res. 1984;12(4):244-9. doi: 10.1177/030006058401200404.

2. Scholer DW, Ku EC, Boettcher I, Schweizer A. Pharmacology of diclofenac sodium. Am J Med. 1986;80(4B):34-8. doi: 10.1016/0002-9343(86)90077-x, PMID 3085490.

3. Savaşer A, Özkan Y, Işımer A. Preparation and in vitro evaluation of sustained release tablet formulations of diclofenac sodium. Farmaco. 2005;60(2):171-7. doi: 10.1016/j.farmac.2004.10.001, PMID 15752476.

4. Faure A, York P, Rowe RC. Process control and scale-up of pharmaceutical wet granulation processes: a review. Eur J Pharm Biopharm. 2001;52(3):269-77. doi: 10.1016/s0939-6411(01)00184-9, PMID 11677069.
5. Agrawal R, Naveen $\mathrm{Y}$. Pharmaceutical processing-A review on wet granulation technology. Int J Pharm Front Res. 2011;1(1):65-83.

6. Lachman L, Lieberman HA, Kanig JL. The theory and practice of industrial pharmacy. Lea \& Febiger; 1986.

7. Jivraj I, Martini LG, Thomson CM. An overview of the different excipients useful for the direct compression of tablets. Pharm Sci Technol Today. 2000;3(2):58-63. doi: 10.1016/s1461-5347(99)00237-0, PMID 10664574.

8. Schmidt PC, Rubensdörfer CJW. Evaluation of Ludipress as a "Multipurpose Excipient" for Direct Compression: Part II: Interactive blending and tableting with micronized glibenclamide. Drug Dev Ind Pharm. 1994;20(18):2927-52. doi: 10.3109/03639049409042688.

9. Shangraw RF. Compressed tablets by direct compression. Pharmaceutical dosage forms: tablets. 1989;1:195-246.

10. Ryakala H, Dineshmohan S, Ramesh A, Gupta VRM. Formulation and in vitro evaluation of bilayer tablets of nebivolol hydrochloride and nateglinide for the treatment of diabetes and hypertension. J Drug Deliv. 2015;2015:827859. doi: 10.1155/2015/827859, PMID 25648606

11. Pesonen $\mathrm{T}$, Paronen P. Evaluation of a new cellulose material as binding agent for direct compression of tablets. Drug Dev Ind Pharm. 1986;12(1113):2091-111. doi: 10.3109/03639048609042625.

12. Mitrevej A, Sinchaipanid N, Faroongsarng D. Spray-dried rice starch: comparative evaluation of direct compression fillers. Drug Dev Ind Pharm. 1996;22(7):587-94. doi: 10.3109/03639049609063212.

13. Shah RB, Tawakkul MA, Khan MA. Comparative evaluation of flow for pharmaceutical powders and granules. AAPS PharmSciTech. 2008;9(1):250-8. doi: 10.1208/s12249-008-9046-8, PMID 18446489.

14. Monteyne T, Vancoillie J, Remon JP, Vervaet C, De Beer T. Continuous melt granulation: influence of process and formulation parameters upon granule and tablet properties. Eur J Pharm Biopharm. 2016;107:249-62. doi: 10.1016/j.ejpb.2016.07.021, PMID 27449628.

15. Johansson B, Alderborn G. The effect of shape and porosity on the compression behaviour and tablet forming ability of granular materials formed from microcrystalline cellulose. Eur J Pharm Biopharm. 2001;52(3):347-57. doi: 10.1016/s0939-6411(01)00186-2, PMID 11677077.

16. CHOWHAN ZT, PALAGYI L. Hardness increase induced by partial moisture loss in compressed tablets and its effect on in vitro dissolution. J Pharm Sci. 1978;67(10):1385-9. doi: 10.1002/jps.2600671014, PMID 702286.

17. Zhang $\mathrm{Y}$, Law $\mathrm{Y}$, Chakrabarti S. Physical properties and compact analysis of commonly used direct compression binders. AAPS PharmSciTech. 2003;4(4):E62. doi: 10.1208/pt040462, PMID 15198557.

18. Sheu M-T, Chou H-L, Kao C-C, Liu C-H, Sokoloski TD. Dissolution of diclofenac sodium from matrix tablets. Int J Pharm. 1992;85(1-3):57-63.

19. Yoshikawa S, Murata R, Shida S, Uwai K, Suzuki T, Katsumata S, Takeshita M. Evaluation of correlation between dissolution rates of loxoprofen tablets and their surface morphology observed by scanning electron microscope and atomic force microscope. Chem Pharm Bull (Tokyo). 2010;58(1):34-7. doi: 10.1248/cpb.58.34, PMID 20045963.

20. Bose A, Wong TW, Singh N. Formulation development and optimization of sustained release matrix tablet of itopride $\mathrm{HCl}$ by response surface 
methodology and its evaluation of release kinetics. Saudi Pharm J. 2013;21(2):201-13. doi: 10.1016/j.jsps.2012.03.006, PMID 23960836.

21. Mallu UR, Nair AK, Bandaru S, Sankaraiah J. Hold time stability studies in pharmaceutical industry [review]. Pharm Regul Aff. 2012;1(4):1-8.

22. Suriyaprakash TNK, Lakshmana Prabu S, Satyam T. In-vitro studies of diclofenac sodium controlled-release dosage from biopolymeric hydrophilic matrices; 2011.
23. Aielo PB, Borges FA, Romeira KM, Miranda MCR, Arruda LBd, L. Filho PN, Drago BdC, Herculano RD de, et al. Evaluation of sodium diclofenac release using natural rubber latex as carrier. Mater Res. 2014;17(suppl 1):146-52. doi: 10.1590/S1516-14392014005000010.

24. Virtanen S, Antikainen O, Räikkönen H, Yliruusi J. Granule size distribution of tablets. J Pharm Sci. 2010;99(4):2061-9. doi: 10.1002/jps.21945, PMID 19780134.

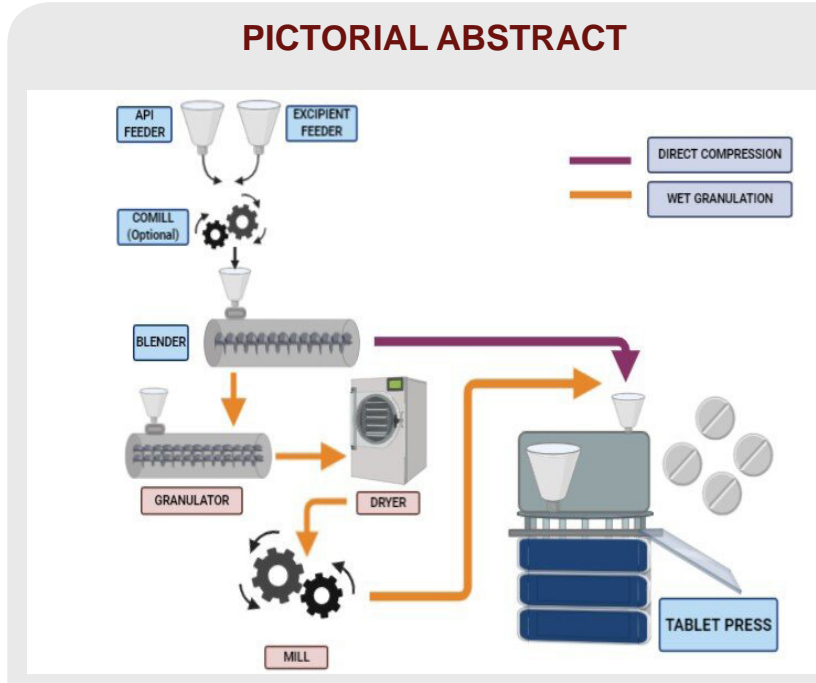

\section{SUMMARY}

The research presented here reveals about the advantages of direct compression over wet granulation technique for tabletting and is chiefly recommended over the other methods owing to its several advantages. Direct compression is proved as a most naive and efficient method due to its minimum number of steps as displayed which makes it more cost-effective. On the other hand, direct compression manufacturing requires minimal processing time, reduced capital, labour, energy cost, and utilities. This research hence proves that direct compression technique would be more beneficial for small-scale industries as it also serves to be a green manufacturing technique without much including the use of any organic solvents and can be developed with a very minimum number of excipients.

\section{About Authors}

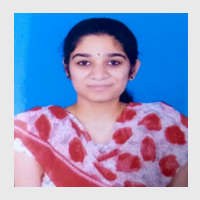

Ms. Divya Dhatri Kara completed her M.Pharm from Manipal College of Pharmaceutical Sciences, Manipal. Currently she is a research scholar in department of pharmaceutics, Manipal College of Pharmaceuticals Sciences. Prior to this she worked as a senior research associate at BBRC, Bangalore. Her area of interest is formulation research and development.

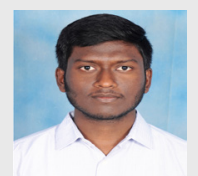

Mr. Hemanth KG completed his M.Pharm in Department of Pharmaceutics from Manipal College of Pharmaceutical Sciences, Manipal Academy of Higher Education, Manipal and his B.Pharm from Al-Ameen College of Pharmacy, Bangalore. He was an Intern in Medical Communications, Novartis HealthCare Pvt Ltd., Hyderabad. He has received Merit scholarship from TATA Trusts for his outstanding score in 1st year M.Pharm. His key interest areas include, 3D Printing, Novel Drug Delivery Systems, Regulatory affairs and Artificial Intelligence.

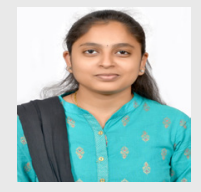

Ms. Hemamanjushree $\mathbf{S}$ completed her M.Pharm in Department of Pharmaceutics from Manipal College of Pharmaceutical Sciences, Manipal Academy of Higher Education, Manipal. She completed her B.Pharm from Government College of Pharmacy, Bangalore. Her key interest areas include Novel Drug Delivery Systems, 3D Printing and Computational fluid dynamics.

Dr. Vamshi Krishna T is faculty at Department of Pharmaceutics, Manipal College of Pharmaceutical Sciences, MAHE, Manipal. His academic interests include the areas of Pharmaceutics, Physical Pharmaceutics and Pharmacokinetics, Advanced Bio pharmaceutics and Pharmacokinetics, Modern Pharmaceutics, Pharmaceutical Product Development. He has briefly worked for Advinus Therapeutics Pvt. Ltd. and has spent about 12 years in academics. Dr. Vamshi Krishna has published over 44 research papers and articles. Dr. Vamshi Krishna completed his Post-doctoral research fellowship on the project entitled "Confocal Raman spectroscopic analysis of cosmetic permeation through human skin" from the Laboratory of Biomedical Vibrational Spectroscopy, Universidade do Vale do Paraiba, Sao Jose Dos Campos, SP, Brazil, in July 2016. He is also a life member of Association. 


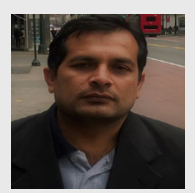

Mr. Mahendra Joshi is Co-founder and Director of IDRS Labs Pvt. Ltd., Bengaluru. He has about 17 years of total experience in Pharma Industries of High repute. Mr Joshi has published several papers in journals of high repute and have presented papers in national and international conference. He has several patents to his credit, $\mathrm{He}$ is recipient of BMS Crystal Award for outstanding technical leadership He is the winner of Indian Leadership Award for Industrial Development for the year 2014 awarded by AIAF, New Delhi, India.

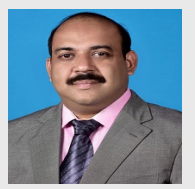

Dr. Girish Pai Kulyadi is faculty at Department of Pharmaceutics, Manipal College of Pharmaceutical Sciences, Manipal Academy of Higher Education, Manipal, India. He has more than 20 years of professional experience both in pharma industry and academia. His area of research expertise include formulation development of novel drug delivery systems, Plant Operations, Advanced Industrial Pharmacy, Validation Concepts, Stability Studies of Drug Products etc. He has published more than 60 research and review articles in peer reviewed journals.

Cite this article: Kara DD, Hemanth KG, Hemamanjushree S, Tippavajhala VK, Joshi M, Kulyadi GP. Detailed Research on a Comparative Evaluation of Diclofenac Sodium Tablets Manufactured by using DC Grade Excipients and Wet Granulation Methods. Indian J of Pharmaceutical Education and Research. 2021;55(3s):s722-s732. 